\title{
Response-Dedicated Trigger Neurons as Control Points for Behavioral Actions: Selective Inhibition of Lateral Giant Command Neurons During Feeding in Crayfish
}

\author{
Franklin B. Krasne and Sunhee Cho Lee \\ Department of Psychology and Brain Research Institute, University of California, Los Angeles, California 90024
}

\begin{abstract}
Feeding behavior suppresses lateral giant neuron-mediated escape behavior in crayfish. The suppression appears to result from reduced transmission to the lateral giants from primary afferents and/or sensory interneurons, while the operation of sensory and motor networks themselves is unaffected. It is suggested that control occurs at the level of the lateral giants because these neurons are pivotal in, and dedicated solely to, producing the type of escape that needs to be controlled. It is hypothesized that response-dedicated sets of neurons that play a similar role will probably be found wherever it is necessary to control particular responses selectively.
\end{abstract}

In a few nervous systems, neurons have been discovered that act as response-dedicated "triggers" or "gates" for particular behavior patterns (see, e.g., Kupfermann and Weiss, 1978; Stein, 1978; Fraser, 1982; Eaton, 1984; Croll et al., 1985b; Brodfuehrer and Friesen, 1986). The neurons are triggers in the sense that occurrence of the behavior patterns is contingent on their associated triggers' firing. They are response-dedicated in the sense that any one trigger neuron is utilized only in the production of one behavior pattern. Although only a few such neurons have been discovered, it can be argued on functional grounds that similar neurons, or small populations playing a similar role, are liable to be very common, existing for most specific motor programs (Krasne and Wine, 1987). One of the most persuasive of these arguments relates to the need, in behaviorally sophisticated animals, to control behavior.

Organisms are often exposed to multiple stimuli, any of which might recruit a behavioral response, and it is essential that the simultaneous occurrence of incompatible responses be prevented. Such coordination requires of nervous systems a capability for controlling responses and for knowing what actions are in fact in progress. Since the information processing responsible for both recognition of stimuli and generation of responses generally utilizes relatively large numbers of neurons, each of which is used in the mediation of many different stimulus-response relationships, it would be difficult to control the probability of one behavior pattern without also affecting others by regulation of activity at perceptual and motor levels. Conversely, determination that a particular act was in progress would

Received June 18, 1987; revised Feb. 16, 1988; accepted Feb. 18, 1988

This work was supported by USPHS Grant NS08108. We thank Joan Gunther and David Anisman for help in running experiments and Eric Vu for comments on the manuscript.

Correspondence should be addressed to Dr. Krasne at the above address.

Copyright (C) 1988 Society for Neuroscience $0270-6474 / 88 / 103703-10 \$ 02.00 / 0$ require circuitry capable of inferring the occurrence of the behavior from the spatiotemporal pattern of activities of many motor elements. Response-dedicated trigger neurons eliminate these difficulties. A behavior pattern can be selectively controlled via its trigger(s), and the occurrence of a behavior is signaled uniquely by the firing of the trigger(s).

The purpose of this paper is to evaluate, in a case in which a dedicated trigger neuron (as well as sensory processing- and motor pattern-generation elements) are identified, whether control really is selectively exercised on the trigger neuron. The behavior examined is the lateral giant escape reaction of the crayfish (Wine and Krasne, 1982), and the control process studied is the suppression of this reaction while the crayfish is engaged in feeding behavior. In addition to its significance for understanding the organization of neural circuits, information on loci of control is also a necessary prelude to evaluating the cellular mechanisms of the control. Similar analyses have previously been attempted for the feeding and withdrawal behavior of the marine opisthobranch mollusk Pleurobranchaea (Kovac and Davis, 1980), but the analysis can be carried much further in the present case because the circuit mediating the behavior is so fully known.

\section{Materials and Methods}

\section{Subjects}

Procambarus clarkii, $2 \frac{1}{2}$ in. in length (rostrum to telson) and of both sexes, were obtained from various local suppliers. They were maintained and tested in individual aerated and filtered 5 gallon aquaria. Once experimentation began, their only food was received during experiments.

\section{Behavioral and anatomical background}

Lateral giant escape is a short-latency stereotyped abdominal flexion that rotates the hind end of the crayfish upward as well as translating the entire animal somewhat upward and forward. It is caused by abrupt mechanical stimulation of the abdomen and serves to remove the abdomen from stimuli that evoke the response. The neuronal circuit mediating the reaction is shown in Figure $1 \mathrm{~A}$. Mechanosensitive afferents throughout the abdomen excite the lateral giant command neurons (LGs) both monosynaptically and via 2 classes of interneurons, the "unisegmental phasics," represented in our experiments by interneuron A, and the "multisegmental tonics," represented by interneuron C. The LGs, in turn, directly excite giant motor neurons (MoGs), each of which innervates most of the phasic flexor ("taillip") muscles on one side of its segment. They also excite the segmental giant neurons (SGs), which, in turn, excite, via both a strong direct connection and a weaker indirect pathway, a population of nongiant "fast flexor" (FF) motor neurons, each of which innervates a subset of the phasic flexor muscles of its segment. The phasic flexor muscles, as well as some of the motor and premotor neurons that produce $\mathrm{LG}$ escape, are also used during other modes of escape (medial giant and nongiant) that will arise in the Dis- 


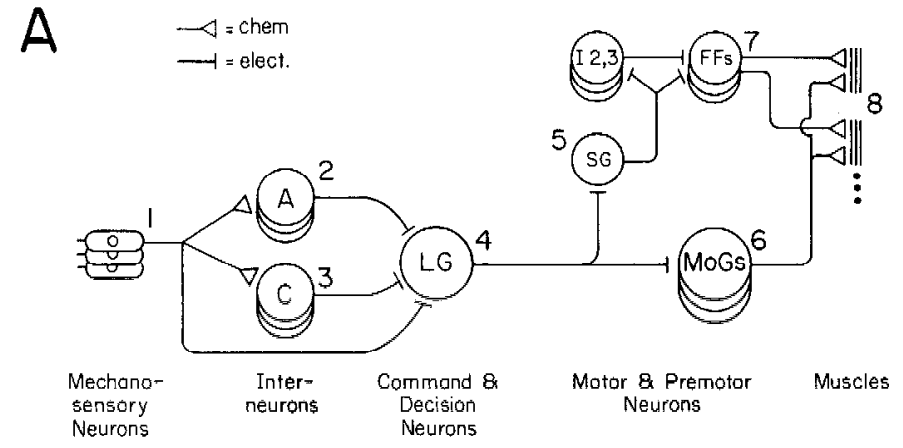

B

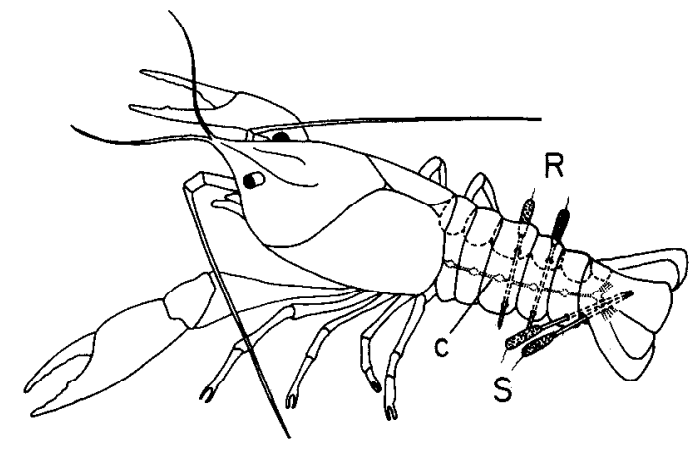

Figure 1. The LG escape reaction circuit and the preparation used for studying it. $A$, The circuit as presently known with identified neurons labeled $(A$ and $C$, sensory interneurons $\mathrm{A}$ and $\mathrm{C}, L G$, lateral giant; $S G$, segmental giant; $I 2,3$, premotor interneurons $\mathrm{I} 2$ and $\mathrm{I} 3 ; F F$, nongiant fast flexor motor neurons; MoGs, giant flexor motor neurons; see text). Points in the circuit that were stimulated or recorded in these experiments are numbered $1-8 . B$, A typical arrangement of stimulating $(S)$ and recording $(R)$ electrodes. $C$, Nerve cord.

cussion. But the LGs are involved only in short-latency upward/forward responses to abrupt caudal stimuli (for reviews of bchavior and circuitry, see Wine and Krasne, 1982; Krasne and Wine, 1984, 1987).

Points in the circuit that were selectively stimulated or recorded via chronically implanted electrodes in freely behaving animals are numbered in Figure $1 A(1-8)$.

\section{Stimulation and recording at selected points in the circuit}

For most experiments, stimulating and recording electrodes were 00 stainless steel insect pins insulated except for a small, bare gap halfway along their lengths. The pins were thrust through the animal such that the gap was positioned over the desired part of the nerve cord or ganglionic roots, and the pins held in place by the exoskeleton (see Fig. $1 B$ ). We refer to such electrodes as "skewer electrodes"; details of their implantation and fabrication are given in Krasne and Glanzman (1986). Electrode leads were run to floats that carried connections for attachment to electronics during experiments. Stimuli were always single $0.1 \mathrm{msec}$ negative-voltage pulses. Recorded action potentials were amplified by high-gain, high-input-impedance differential amplifiers.

Point 1: primary afferents. Bipolar skewer electrodes were chronically implanted on roots $2-4$ of the last abdominal ganglion. Stimuli were single-voltage pulses, which mimic the abrupt mechanical stimuli that naturally evoke escape.

Point 2: interneuron A. Bipolar skewer electrodes implanted on the ventral side of the nerve cord (as in Krasne and Glanzman, 1986) readily recorded firing of the axon of interneuron A (see Fig. 4), which travels near the ventral surface of the cord and is the largest axon of the cord except for the giants (medial and lateral). Interneuron A spikes could be uniquely recognized as the largest (nongiant) spikes that could be recruited by stimulation at point 1 . (See below for further details.)

Point 3: interneuron $C$. The axon of interneuron $\mathrm{C}$ travels directly beside that of interneuron $\mathrm{A}$ and is about half its diameter. It was recorded by monopolar skewer electrodes implanted on the ventral side of the abdominal nerve cord at 2 anterior-posterior levels, each of which was recorded against a common third skewer electrode not in contact with the cord. During experiments on feeding, interneuron $C$ was identified by the following criteria: (1) it was the next large ipsilateral unit after interneuron $A$ to be recruited in an ascending stimulus series; (2) its spike amplitude was a little less than half and its conduction velocity about $60 \%$ that of interneuron $A$; and (3) it fircd repetitively to single, strong root shocks. In separate experiments, it was established that units meeting these criteria also responded to contralateral water currents and to sensory root shocks; taken together, these characteristics uniquely identify interneuron C (Sigvardt et al, 1982).

Point 4: lateral giants. Bipolar skewer electrodes were placed on the dorsal surface of the cord. These recorded huge spikes followed by volume-conducted flexor muscle potentials when the LGs fired (Fig. 3). No other response produced by abdominal stimuli produced a similar profile of activity. In experiments where lateral giants were to be stimulated to examine transmission in motor circuitry, very narrow gaps in the insulation of the skewer electrodes were positioned over a single (left or right) lateral giant axon.

Point 5: segmental giants. Although the only known function of the segmental giant is as an interneuron in the motor portion of the $L G$ circuit (see Fig. 1A), it also has a peripheral axon in the first root that betrays the neuron's presumed evolutionary derivation from a swimmeretle motor neuron (Roberts et al., 1982). No comtemporary function of this axon has yet been discovered, but its antidromic activation by first root shocks provided a convenient way to recruit the segmental giant. First root-stimulating electrodes were pairs of uninsulated $3 \mathrm{~mm}$ stainless steel wires wrapped around a second ganglion sternal rib and first root, where the root passes adjacent to the rib. Stimuli were 0.1 msec shocks set just suprathreshold for recruiting the segmental giant, as indicated by recruitment of phasic flexor axons and muscle potentials and interneuron I2 (see Fig. 6); I2 firing was monitored by a dorsally placed recording skewer on a caudal connective.

Point 6: motor giants. Skewer electrodes with narrow gaps were implanted with the gaps just rostral to a ganglionic third root for the purpose of examining transmission from the LGs to the MoGs (third roots carry all flexor motor axons, and only such axons, to the periphery). Each MoG is excited by the ipsilateral, but not contralateral, LG (as well as by both medial giants) (Selverston and Remler, 1972; Mittenthal and Wine, 1973). Examination of transmission from the ipsilateral LG to the MoG using chronically implanted recording electrodes is complicated by the fact that commissural synapses between the LGs of each side (Watanabe and Grundfest, 1961) cause the firing of the LG contralateral to the stimulated LG at about the same time as the firing of the recorded MoG. At the recording electrode, the contralateral LG causes a field potential that is about the same size as that produced by the recorded MoG and is easily confused with it. To avoid this problem, we usually recruited the ipsilateral LG indirectly by stimulating the contralateral LG. Since the contralateral LG was then refractory when the ipsilateral LG fired, the MoG spike occurred against a quiet baseline (see Fig. 5).

Point 7: nongiant fast flexor molor neurons (FFs). The FFs were recorded by narrow-gap skewer electrodes placed just rostral to a third root of the second abdominal ganglion (see Fig. 6). Under the circumstances in which $\mathrm{FF}$ firing was assessed, only $\mathrm{FF}$ firing (and muscle responses) produced significant field potentials at these electrodes.

Point 8: phasic flexor muscles. The electrodes used to record FF activity also picked up volume-conducted muscle potentials.

Behavioral responses. Visually observed tailflips (and associated flexor muscle potentials) to root shocks at point 1 usually occurred within 20 msec (latency to muscle potential) of the stimulus. Such short-latency responses to caudal stimuli are known from previous work (Wine and Krasne, 1972; Reichert and Wine, 1983) to always be mediated by the LGs, and firing of the LGs did in fact always precede such responses in the present experiments. On rare occasions, behavioral responses with a latency greater than $20 \mathrm{msec}$ occurred. Such responses were probably nongiant-mediated (see Wine and Krasne, 1972, and Discussion), but since our oscilloscope sweep was always $20 \mathrm{msec}$ long, we do not have direct evidence on this point. For purposes of analysis, we did not consider such responses as LG-mediated and scored them as non-responses.

\section{Experimental procedures}

Basic design. In all experiments, escape circuit function was evaluated during 3 periods of about equal length: (I) prefood-initial thresholds or baseline responses were determined prior to introduction of food; 
(II) food-food was introduced, and while the animal ate, thresholds or response amplitudes were again measured; (III) postfood=food was removed and measurements were repeated. Period I was usually pre= ceded by a "pretest" during which thresholds were located and other parametcrs needed for the experiment proper were determincd.

General procedures. Electronic equipment was connected to floats 30 inin before the start of experiments.

Liver was used for all tests of effects of feeding behavior. Several days prior to the commencement of experiments, animals were fed pieces of liver. Once accustomed to this food, most animals started feeding within $30 \mathrm{sec}$ of its being dropped into their aquaria and would usually continue to feed for at least $30 \mathrm{~min}$. Food was removed by grasping it with forceps and slowly lifting it to the water surface. Most animals released the liver either before or when it reached the water surface. However, sometimes food had to be physically torn away from animals. A few crayfish in which this was a regular occurrence were discarded. In our initial experiments we compared the effects of eating "small" $\left(1-2 \mathrm{~cm}^{2} \times 0.5\right.$ $\mathrm{cm}$ ) and "large" $(9-18 \times 9 \times 2 \mathrm{~cm})$ pieces of liver, because in an earlier study (Bellman and Krasne, 1983) portability of the liver affected the results obtained (see below); however, here both sizes of liver gave similar results, so all further experiments used pieces of food about 2.5 $\mathrm{cm}^{2} \times 0.5 \mathrm{~cm}$.

At least $24 \mathrm{hr}$ elapsed between experimental sessions.

Threshold-tracking experiments. In experiments in which the sensory threshold of LGs or interneurons A or C were examined, stimuli were presented at fixed intertrial intervals and varied in intensity according to the rule that if a response did not occur on a trial, stimulus intensity was increased by a fixed increment, $\Delta$, for the next trial, and conversely (the values of $\Delta$ and intertrial interval depended on the nature of the particular experiments; see below). This procedure, which we call "threshold tracking," is illustrated in Figures 2-4.

Thresholds were estimated from transitions between responding and nonresponding during tracking. When a response failed to occur at stimulus intensity $x$ and occurred on the subsequent trial at intensity $x$ $+\Delta$, the threshold of the moment was estimated as $x+\Delta / 2$, and conversely for transitions from responses to non-responses when stimulus intensity was decreased. The estimates obtained from individual non-response-to-response and response-to-non-response transitions during a test period were averaged to obtain an overall estimate for the period.

Periods I-III were always begun with stimuli that were just below the previously established threshold (i.e., the largest known subthreshold stimulus), and tracking continued (using the preestablished $\Delta$ ) for a prescribed number of trials. The number of trials and their spacing depended on the characteristics of the unit being tracked. For tests of LG, which is quite prone to habituating (Krasne, 1969; Wine et al., 1975), interstimulus intervals were kept relatively long ( $3 \mathrm{~min}$ ) and the number of tracking trials per period minimized ( 3 trials). Therefore, $\Delta$ was made large $(12-20 \%$ of initial threshold values) to insure that a reasonable range of stimulus intensities could be examined despite the small number of test trials. Methods for behavioral tests were identical to those for $\mathrm{LG}$ tests. For interneuron $\mathrm{A}$, which is relatively resistant to habituation, a shorter intertrial interval $(30 \mathrm{sec})$, more trials per test period (15), and a smaller $\Delta$ ( $5 \%$ of average initial threshold) were used to increase the precision of threshold estimates. For interneuron $C$, whose tendency to habituate is intermediate, intertrial interval was 1 min, trials per period $12-15$, and $\Delta 5 \%$ of average threshold.

As explained above, it was desirable during experiments on the LGs to minimize the number of tracking trials, which were limited to $3 /$ test period. Thus, during period II, when threshold generally rose because of feeding, there were often no responses to any of the 3 stimuli (the first being just below the pretest control threshold and the second and third being $1 \Delta$ and $2 \Delta$, respectively, above). Thus, there were often no non-response-to-response transitions from which to estimate threshold. In such cases, the least the threshold could have been, had testing been more protracted, was $2.5 \Delta$ above the control threshold, and this conservative value was entered in data analyses. Conversely, if no response failure had occurred by the end of a descending series of stimuli (as sometimes happened during period III, when thresholds tended to fall), threshold was taken as $2.5 \Delta$ below the control. These procedures were needed only for LG testing.

Determining $M o G$ firing probability. The lateral (and medial) giants excite the MoGs via very effective synapses that continue to recruit MoG firing perfectly even during feeding (see Results). However, because these synapses are so effective, it was possible that the EPSPs produced in the MoGs by firing of the LGs might have been reduced during feeding and yet still have been above the MoG firing level. The MoGs are normally prevented from producing multiple spikes per es= cape response by a "recurrent inhibitory" circuit that is activated by LG or MG firing and strongly inhibits the MoGs soon after $\mathbf{L G}$ firing (see Fig. 5) (Hagiwara, 1958; Mittenthal and Wine, 1973). At 80-200 msec after an LG firing, the recurrent inhibition has worn off to a point at which the EPSP produced in the MoGs by a second test firing of the LGs is very close to the MoGs' firing level. Under these circumstances, any inhibition of LG-to-MoG transmission caused by feeding would be clearly manifest as a lowering of firing probability.

Thus, experiments on LG-to-MoG transmission utilized pairs of LGstimulation pulses. The first pulse allowed examination of the resting efficacy of transmission from LG to MoGs, while the second pulse occurred during a period of lowered MoG firing probability. During pretesting, the threshold of the $L G$ to direct stimulation was determined and an interpulse interval for which the second test LG-MoG EPSP would be near the MoG threshold found. Then stimulus pairs utilizing several interpulse intervals in a range where MoG firing was probabilistic (see Fig. $5 B$ ) were given during periods I-III to examine effects of feeding. Approximately 6 pulse pairs at 1 pair $/ 3$ min were given per period. Enough daily sessions were run to accumulate about a dozen trials per animal in which period I firing probabilities were about $70 \%$.

Examination of $L G-F F-$ muscle transmission. In principle, it would have been desirable to explicity examine transmission between the LGs and FFs. However, at about the same time that firing of the LGs evokes firing of FF axons, it also evokes firing of cord interneurons that pass near the FF recording electrodes. This makes identification of FF activity uncertain. Therefore, we examined the terminal segment of the pathway by directly exciting the SGs and recording FF and muscle potential activity. Transmission between LGs and SGs is, in any case, a very unlikely site of transmission modulation because the IG-SC contact is an exceptionally efficient electrical synapse with a very high safety factor (Roberts et al., 1982). By contrast, the baseline EPSPs of thc approximatcly $9 \mathrm{FF}$ motor neurons excited by the SG of a hemiganglion are poised close to the FF's critical firing levels, making this synapse a plausible site of modulation (Roberts et al., 1982). The amount of FF firing, measured by the area under the compound third root spike, provides a sensitive test for factors affecting transmission at synapses between segmental giants and FFs (and also along the relatively weak SG-CDI-FF pathway). Recording of volume-conducted phasic flexor muscle potentials in the same experiments also allowed assessment of the constancy of transmission between FFs and muscles.

Evoked FF and muscle potential responses were tested at $3 \mathrm{~min}$ intervals, 10 test trials being given during each experimental period. Since the first root-stimulating electrodes used to excite SGr antidromically (see above) could, at higher voltages, excite sufficient first root sensory axons to cause LG firing, care was taken to use stimuli just suprathreshold for cxciting the SG axon. This was accomplished by presenting, for each test trial, a series of first root shocks (at $0.1 \mathrm{~Hz}$ ) that started below the SG threshold and gradually increased in intensity until the SG fired (as indicated by the sudden appearance of a compound FF spike, a muscle potential, and a contralateral 12 axon spike at cord electrodes (see Fig. 6B).

\section{Results}

The suppression of behavioral LG escape responses during feeding is illustrated in Figure $2 A$. Prior to introduction of food, the stimulus voltage threshold for evoking an escape response was between 2.5 and 2.75 (arbitrary) units. During feeding it rose to greater than 3.0 units. Following feeding it returned to its prefeeding level. Twenty animals were tested in this way. Threshold typically rose $10-30 \%$ in period II (relative to I) and usually fell slightly below prefeeding levels when the food was removed. Figure $2 B$ gives means for all animals. The rise from period I to II and the fall from period II to III were significant at $p<0.01$ (2-tailed Wilcoxon tests). The period III drop below period I could have been due to sensitization caused by food removal (see Krasne and Glanzman, 1986). The lower level in period III relative to that of period I was significant at $p<0.05$ (2-tailed Wilcoxon test). 
Figure 2. Suppression of escape behavior during feeding. $A$, Each trial is represented by a point whose ordinate value is the stimulus voltage (in arbitrary units); if the point is filled, the animal responded, and if open, it did not. Periods of the experiment are indicated on the abscissa. Animals were allowed to feed during period II. The dashed horizontal line indicates the estimated threshold for period I (the prefood test period; see Materials and Methods). $B$, Mean threshold relative to period I for 20 animals (error markers, SEMs); animals feed during period II. $C$, Mean of percentage responses to a constant stimulus in 5 animals; animals feed during period II. $D$, Like $B$, except that food is inaccessible; animals searched for it in response to chemical cues. $E$, Effect of cutting nerve cord between abdomen and thorax; suppression during period II feeding no longer occurs. The shaded bars give results for the same animals prior to nerve cord severance.
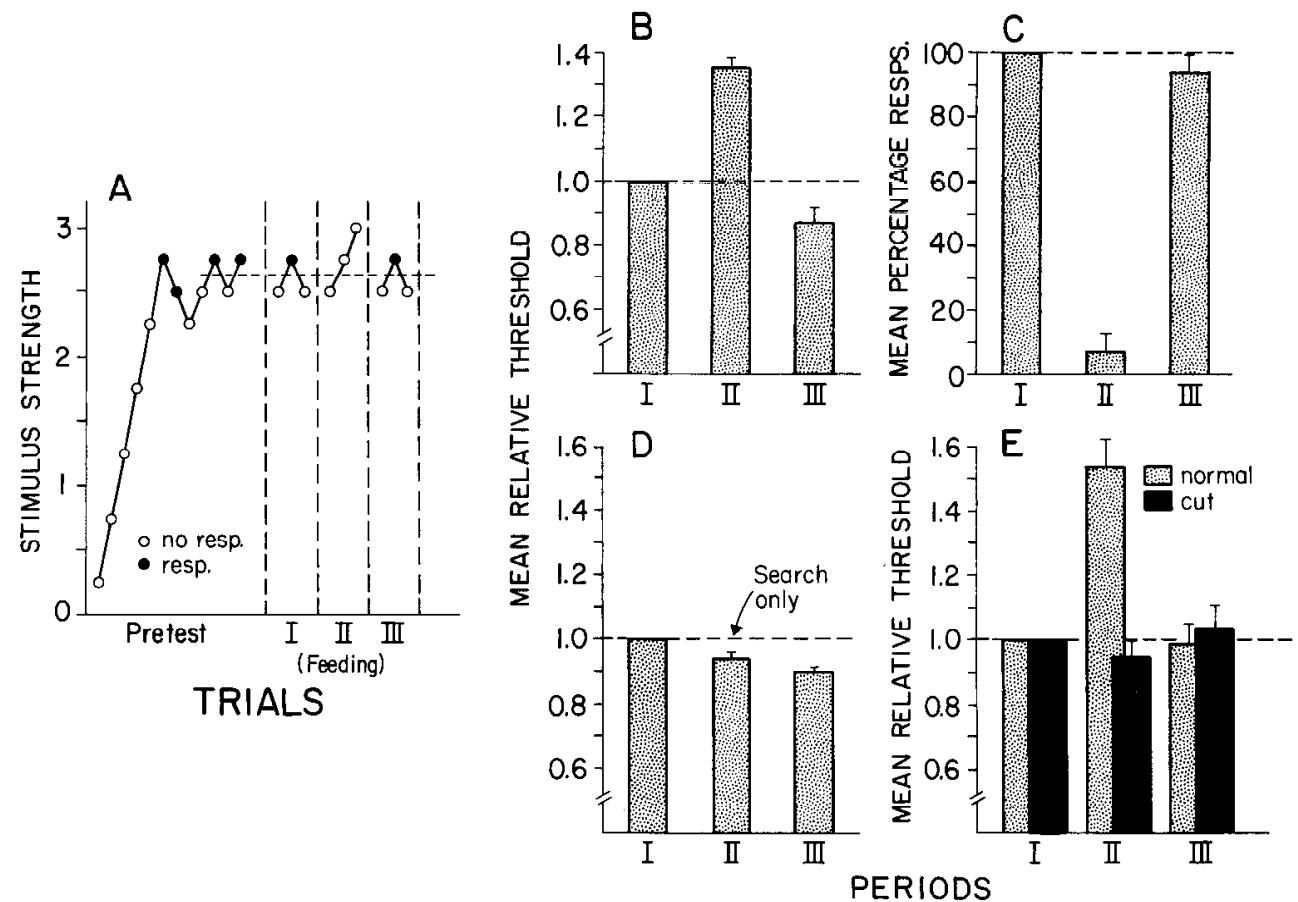

In 5 of the above animals, enough test sessions were run to allow estimates of response probabilities of individual animals (Fig. 2C). Just-suprathreshold stimuli, which by construction always caused responses during period I and were, on the average, $9 \%$ above threshold, evoked responses only $7 \%$ of the time during feeding but were $92 \%$ effective in evoking responses once the food was removed.

The 30\% rise of threshold described above is, to some extent, an underestimate of the suppressive effect of feeding, because during feeding we never tested stimuli greater than $2 \Delta$ above period I threshold ( $\Delta$ is the amount by which stimulus levels were changed from one trial to the next; see Materials and Methods). On the other hand, animals that did not respond to a stimulus $\Delta$ above prefeeding threshold responded about $20 \%$ of the time to a stimulus $2 \Delta$ above threshold. We conclude that the suppressive influence occurring during feeding is reliable but not terribly strong.

The suppression of escape seems to be related to the actual engagement in consumption rather than to attentional variables, because animals that are actively searching for inaccessible food in response to chemical cues do not show elevated thresholds (Fig. 2D) (average threshold elevation during search less than during feeding; $p<0.02 ; 2$-tailed $U$ test).

A previous analysis of effects of feeding on nongiant-mediated ("voluntary"; see Discussion) tailflip escape behavior (Bellman and Krasne, 1983) found that nongiant escape was suppressed when an animal was feeding on large pieces of food that it could not carry with it as it escaped, but that it was enhanced in probability during consumption of small, portable bits of food. This is not the case for suppression of LG escape. Five animals were tested 3-5 times each with both small and large pieces of food like those of the previous study. In none was less suppression seen with the small than with the large pieces of food (indeed, presumably by chance, suppression was actually greater in 3 of the 5 animals during tests with small pieces of food).

Feeding is predominantly an activity of the rostral half of the animal, while LG escape circuitry is largely in the abdomen. To determine whether the suppressive influence descends to the abdomen via neural or hormonal pathways, we tested for suppression during feeding in 5 animals whose nerve cords had been transected between abdomen and thorax (methods as in Krasne and Glanzman, 1986). None showed any sign of suppression of LG cscapc during fecding (statistically insignificant mean threshold decrease of 5\%). Because suppression is so reliable in intact animals, its absence, even in these few animals, is statistically reliable $(p<0.002$, 2-tailed $U$ test on percentage threshold increase during feeding in cut vs normal animals).

The remainder of this paper concerns the locus of transmission blockage within the LG reaction circuit during feeding.

\section{Transmission between afferents and LGs}

The sensory threshold of the LGs reliably rises during feeding. Figure 3 shows a sample session and summary results for 20 animals. The rise in threshold is highly reliable statistically ( $p$ $<0.01$ for periods I vs II and II vs III; 2-tailed Wilcoxon tests).

To control for the possibility that the threshold rise between periods I and II was due to habituation, 5 animals were run in dummy experiments that were identical to the feeding experiments except that food was not given. The mean threshold rise between periods I and II in such control experiments was $-0.5 \%$ ( $\mathrm{SEM}=6.3)$, compared to $33.5 \%(\mathrm{SEM}=4.6)$ for the same animals tested with food $\left(p<0.02, t_{4}=4.36\right)$.

\section{Transmission between afferents and sensory interneurons}

The effects of feeding on transmission between afferents and interneuron $A$ were examined in 5 animals whose LG thresholds were also examined (animals a-e, Fig. 4, D, E, and illustrative session of $4 C$ ). Although LG threshold rose during feeding in all 5 animals, no effects of feeding on the interneuron $A$ threshold were seen. Effects of feeding on the interneuron A threshold alone were also examined in 7 additional animals. Overall, the interneuron A threshold, relative to period I, was 99\% (SEM = 

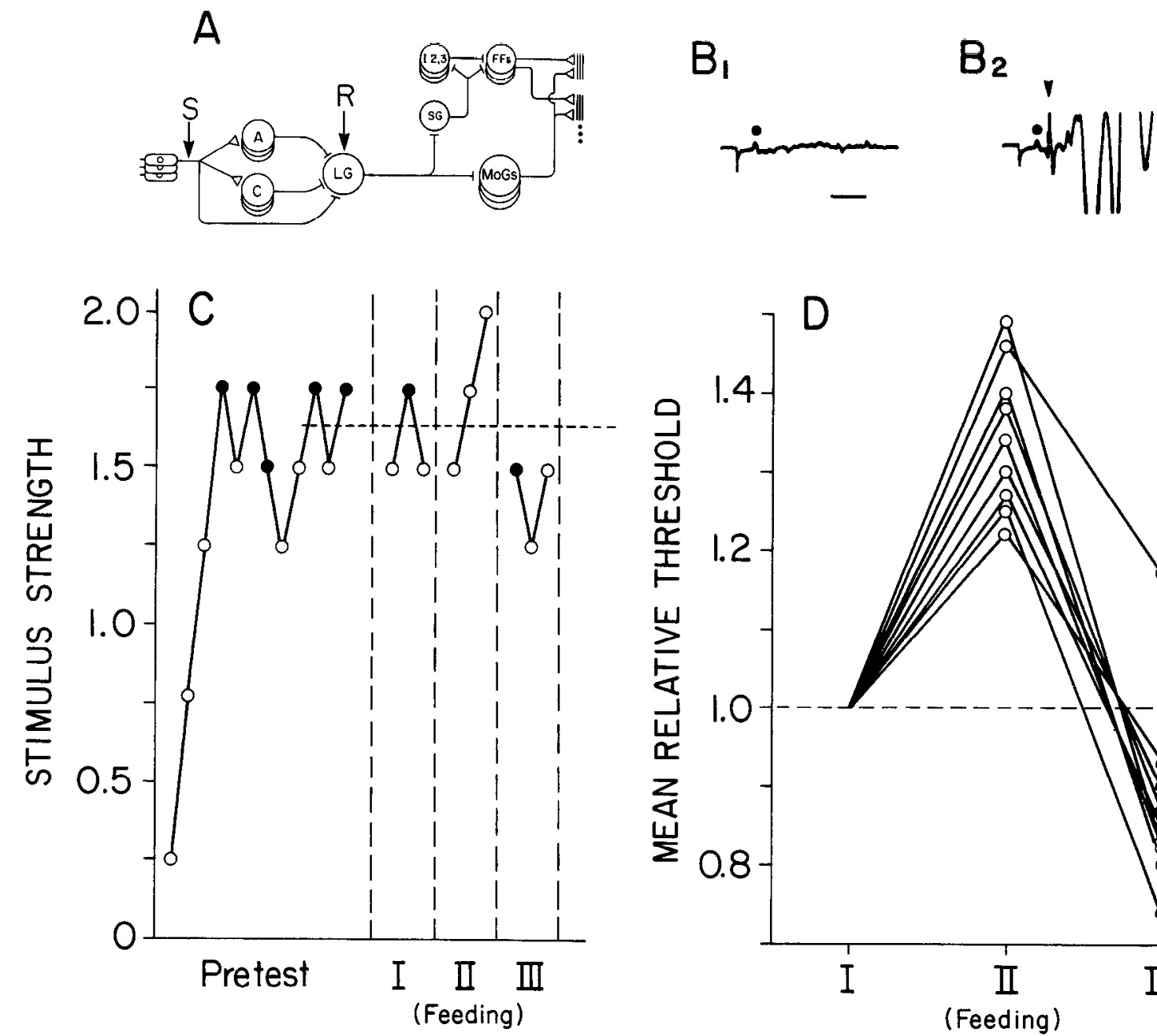

TRIALS

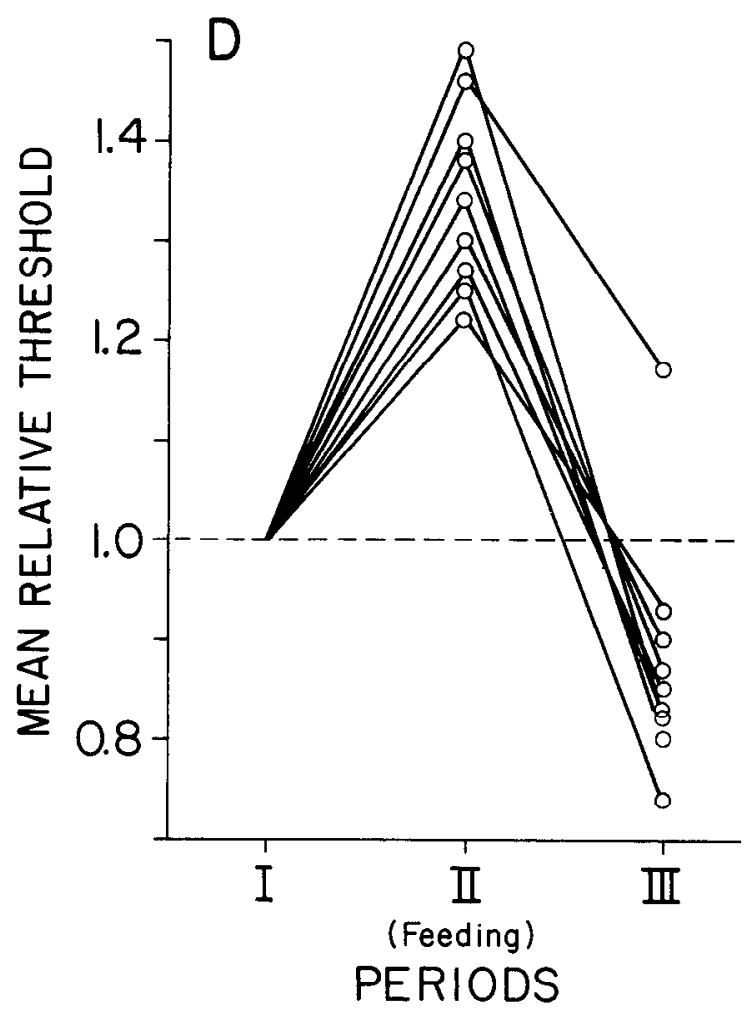

Figure 3. Effect of feeding on stimulus threshold for LG firing. $A$, Location in circuit of stimulating $(S)$ and recording $(R)$ electrodes. $B$, Sample traces. $B_{1}$ is just below and $B_{2}$ just above threshold for LG firing. The dots mark interneuron A spikes, the triangle an LG spike that is followed by flexor muscle potentials. Calibration, $4 \mathrm{msec}$. $C$, Results from illustrative experimental session. $D$, Mean relative thresholds for individual animals based on an average of 2.5 experimental sessions per animal.

0.9) during period II and 97\% (SEM $=2.0$ ) during period III. Thus, transmission from afferents to interneuron $\mathrm{A}$ was not increased during feeding.

Figure $4 F$ also shows results for 4 animals in which transmission from afferents to interneuron $\mathrm{C}$ was examined; again, feeding was without effect.

\section{Transmission in motor circuitry}

Changes in transmission between afferents and LGs can entirely account for the suppression of escape behavior during feeding because the occurrence of short-latency behavioral responses was perfectly correlated with $L G$ responses. However, this leaves open the question of whether there is any modulation of tailflip production motor circuitry affecting vigor of tailflips that occur to stimuli that are strong enough to evoke responses despite engagement in feeding.

Transmission between IGs and MoGs. Transmission from the LGs to the motor giant neurons was examined in 4 animals. These animals were tested with pairs of LG firings, the first of which assessed the basic ability of the LG to recruit the MoGs and the second of which, 80-200 msec later, tested transmission when the excitability of the MoGs was partially reduced by recurrent inhibition (see Materials and Methods). The second test firing of the pair provided a much more sensitive test than the first for small variations in efficacy of transmission during feeding, since, on the first test, the EPSP may have been so far above the MoGs' firing level that reductions due to feeding would not have caused firing failures.

As is seen in Figure 5, the MoGs were always recruited by the initial LG firing before, during, and after feeding. Furthermore, even when the probability of MoG firings was lowered to about $70 \%$ at the second LG firing, feeding was still without effect on MoG firing probability.

Transmission from SGs to FFs and muscles. Efficacy of transmission from SGs to FFs is normally rather marginal and thus would be a sensitive target for modulatory processes, which, in fact, are believed to occur as part of the motor pattern-generation process (Dumont and Wine, 1987). Neuromuscular transmission itself is also a possible site of modulation, because the phasic flexor muscles are innervated by centrally originating peripheral inhibitors (see Wine and Mistick, 1977). Transmission in the FF pathway was thus examined in 3 animals. 
A

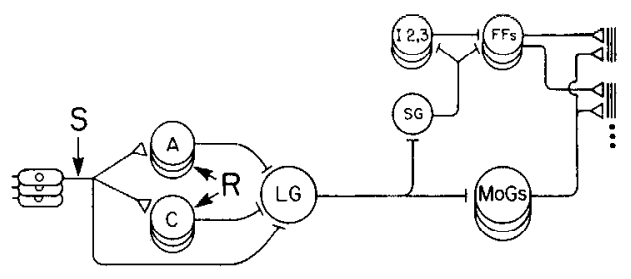

$B_{1}$

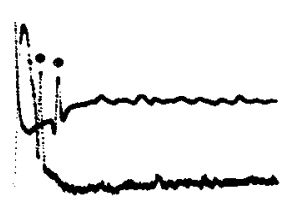

$B_{2}$

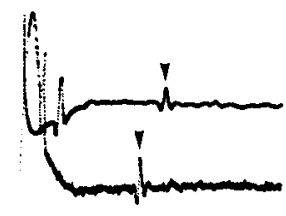

D LATERAL GIANT

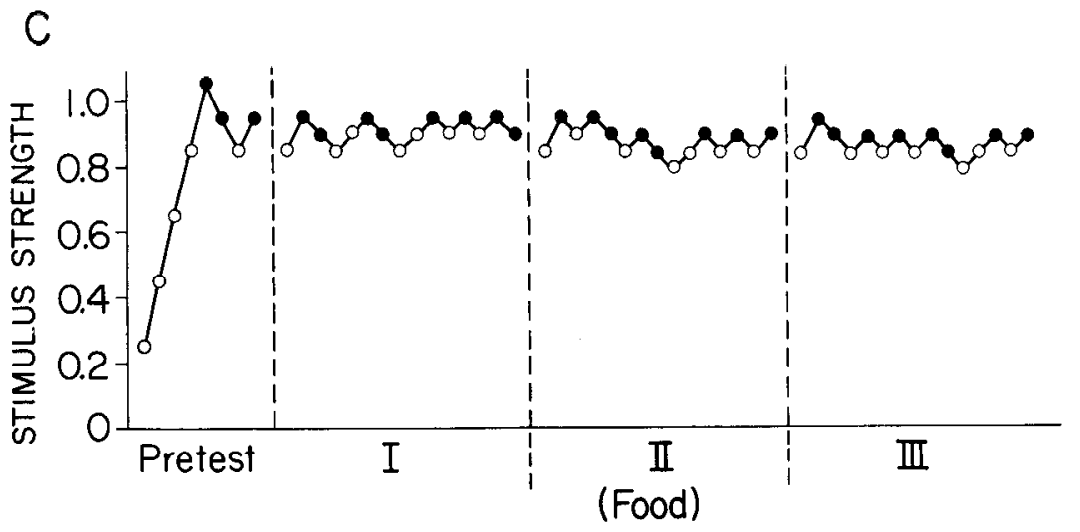

PERIODS

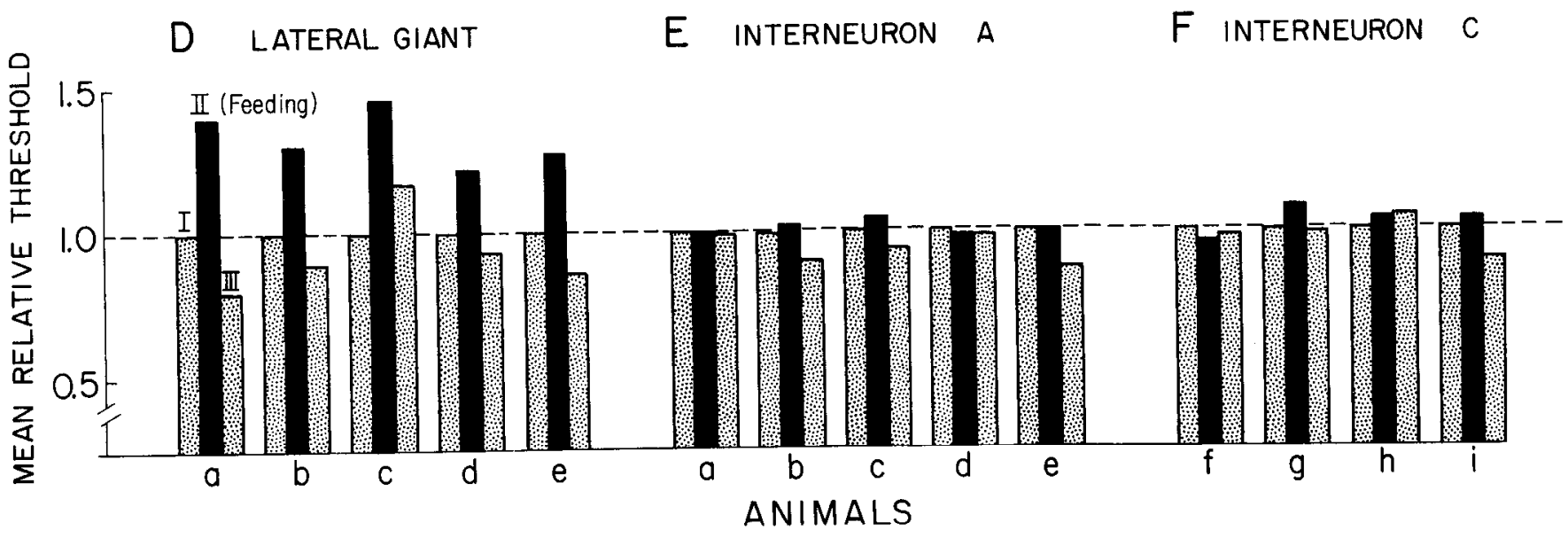

Figure 4. Lack of effect of feeding on stimulus thresholds for interneurons A and C. $A$, Stimulating $(S)$ and recording $(R)$ loci. $B_{l}$, Responses to stimuli suprathreshold for interneuron A, but subthrcshold for C. Upper trace from connective electrode between ganglia 2 and 3 ; lower between 4 and 5 . The interneuron A spike is marked by a dot on each trace. $B_{2}$, Stimuli suprathreshold for both interneurons A and C. Interneuron C spikes marked by arrowheads. Note that A propagates faster than $\mathrm{C}$. Calibration, $2 \mathrm{msec}$. $C$, Illustrative session on interneuron $\mathrm{A}$. $D$, Mean relative sensory thresholds for LGs during periods I-III in 5 animals $(a-e)$ in which interneuron A was also tested. $E$, Results for interneuron A in animals $a-e$; all animals fed vigorously during period II. LG and interneuron A test sessions, 2-5 each, were given in random order. $F$, Results for interneuron $\mathrm{C}$ in 4 other animals.

However, as shown in Figure 6, neither FF firing nor flexor muscle potentials showed any sign of being altered during feeding. There were sometimes gradual drifts of responses upward or downward throughout the course of experiments, but there was no sign of any effect of feeding.

\section{Discussion}

The results of this study are summarized in Figure 7. From it we conclude that suppression of LG responses during feeding is probably due to suppression of effective transmission at inputs to the LGs from primary afferents and/or sensory interneurons and that neither the operation of the sensory network preceding the LGs nor that of the motor network following the LGs is altered. A similar conclusion probably holds for the suppression of LG responding that occurs when crayfish are restrained (see Krasne and Wine, 1975). Though restraint-induced suppression is less fully analyzed than feeding-induced suppression, the similarities between them lead us to suspect that they utilize a common pathway and mechanism.

The above conclusions follow most straightforwardly from our data and are also supported by logical considerations (see below). However, we must acknowledge that we have examined only one exemplar of each of the 2 known types of sensory interneuron. It remains conceivable that suppression of transmission between afferents and sensory interneurons occurs in other members of these 2 classes or in neurons of other, as yet undiscovered, types.

Though control of the kind illustrated here is crucial in combining individual actions into integrated behavior, there are at present few cases where the mechanisms used can be analyzed. However, the locus of feeding-induced suppression is now sufficiently circumscribed to make cellular analysis possible. Available information (Glanzman and Krasne, 1983, 1986) suggests that control may be exerted via a serotonergic pathway and is probably not mediated via direct classical postsynaptic inhibition of the LGs, but confirmation and many further details are needed.

It is interesting that a serotonergic system in lobsters and crayfish has also been seen as mediating a state in which fighting and defense predominate over flight behavior (Kravitz, 1986). From this point of view, it might be supposed that feeding suppresses escape because it promotes this serotonergic "fight- 

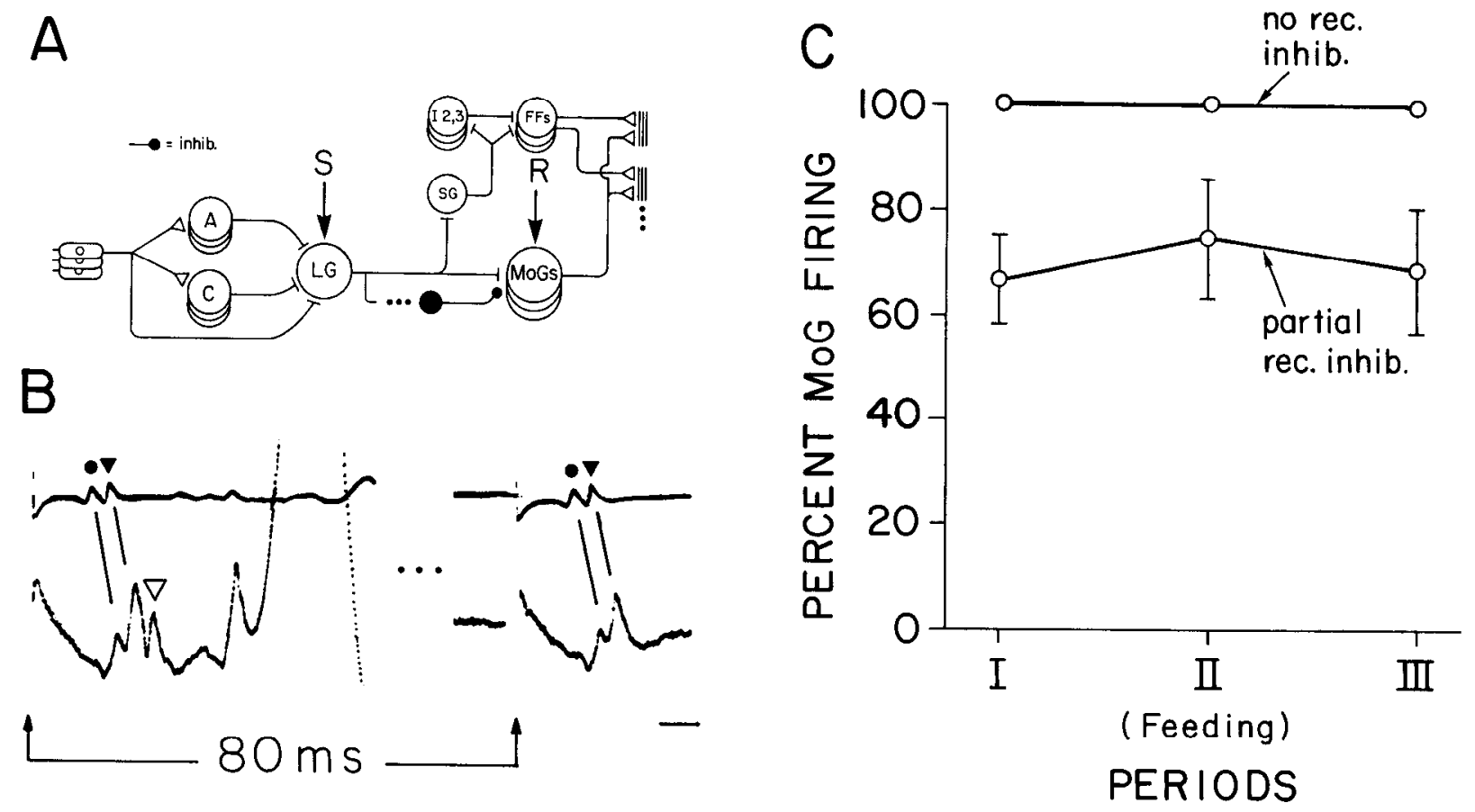

Figure 5. Lack of effect of feeding on transmission from lateral giants to motor giants. $A$, Stimulating $(S)$ and recording $(R)$ loci. $B$, Illustrative response to paired stimulations of LG contralateral to the MoG recording electrodes (see text). The upper trace, from a dorsal connective electrode, shows the stimulated (contralateral; filled circle) and commissural synapse-produced (ipsilateral; filled triangle) LG spikes to each of the 2 pulses. The lower trace from an electrode on the flexor motor root contralateral to the stimulating electrode shows the same 2 spikes and, at the first stimulation, the MoG spike (open triangle); these are followed by FF compound spike and muscle potential. At the second stimulation, 80 msec after the first, there was, in this case, sufficient residual recurrent inhibition to prevent MoG from firing. Calibration, 0.5 msec. $C$, Percentage of trials on which MoG fired during periods I-III. The upper curve ("no recurrent inhibition") gives responses to the first pulse of the pair, and the lower curve "partial recurrent inhibition" gives responses to the second. In neither case did feeding (period II) lower the probability of MoG firing.

over-flight" state. Restraint, which may make escape physically impossible, might also promote this serotonergic state.

The present results, as well as being important as a prelude to more detailed physiological analysis, have significance for our understanding of the organization of neural circuitry.

Like LG escape, most kinds of behavior need to be subject to control that ordinarily must be exercised selectively, affecting a limited class of behavior patterns and sparing others. We will focus here on suppressive control. The neural circuitry that generates movement patterns is often multifunctional, with a given set of neurons being able, with suitable triggering and modulation, to generate a substantial range of behavior patterns (e.g., Bernstein, 1967; Berkinblit et al., 1978a, b; Kramer et al., 1981; Flamm and Harris-Warrick, 1986a, b). In cases in which suppression of behavior is selective in the sense that the patterns to be suppressed are those produced by a given pattern-generation network, the control can be achieved by affecting any subset of neurons whose operation is sufficiently pivotal in the successful operation of the circuit. However, where different patterns producable by a given network need to be controlled differentially, selective control may become difticult to achieve unless there are elements within the network that are both dedicated to and pivotal in the production of the to-be-suppressed patterns. For if there are no such elements, control must be achieved by altering the operation of circuit elements that also participate in the production of other behavior patterns, without affecting such production. While it may be theoretically possible to design circuits that work in this way (see current thinking on parallel distributed processing; McClelland and Rumelhart, 1986;
Rumelhart and McClelland, 1986), the form they might take is not easy to envisage.

Let us consider how control is handled in the escape behaviorproducing system of the crayfish. Figure 8 portrays major relevant features of crayfish escape circuitry (see Krasne and Wine, 1984, 1987). In Figure 8, the circuitry innervated by the LGs is similar to that of the previous figures, but has been expanded to indicate segmental distribution in the abdomen. Pictured in addition are the medial giant neuron (MG), whose firing causes a tailflip that projects the animal directly backward (in contrast to the upward/forward trajectory of LG escape) and the inferred, but as-yet-unidentified, set of neurons (non Gs) that mediate a large class of tailflip escape responses that are produced without firing of the giants (Kramer and Krasne, 1984; Krasne and Wine, 1984). These occur at longer latencies than the $L G$ and $M G$ responses and are much less stcrcotypcd in form. Study of the circuit will show that the FFs are used in all tailflips, whereas the SGs and MoGs are used only in LG and MG tailflip production. MG and LG tailflips differ primarily in the segmental distribution of MoG activity recruited (and, to a lesser extent, in the segmental patterns of biasing of FF motor neurons by "feed-forward" inputs from the sensory system also portrayed in Fig. 8; Dumont and Wine, 1987).

If this motor pattern-generating circuit were only utilized for producing I G responses, such responses could be suppressed in a variety of ways. The activity of the output neurons could be suppressed; the MoGs, together with premotor neurons like the SGs and $12 / 3$ (as well as other members of this set known to exist but not yet specifically identified; Kramer and Krasne, 

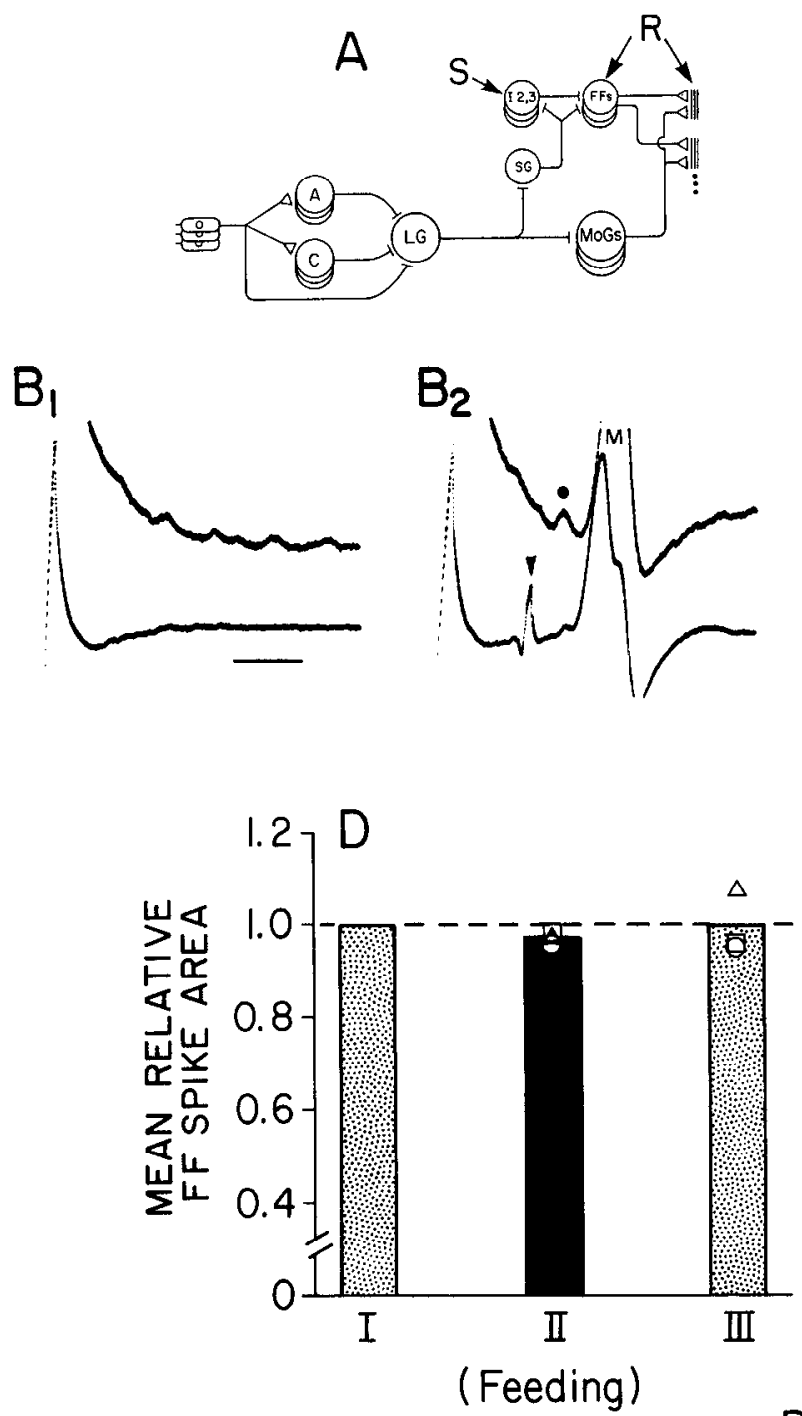

PERIODS
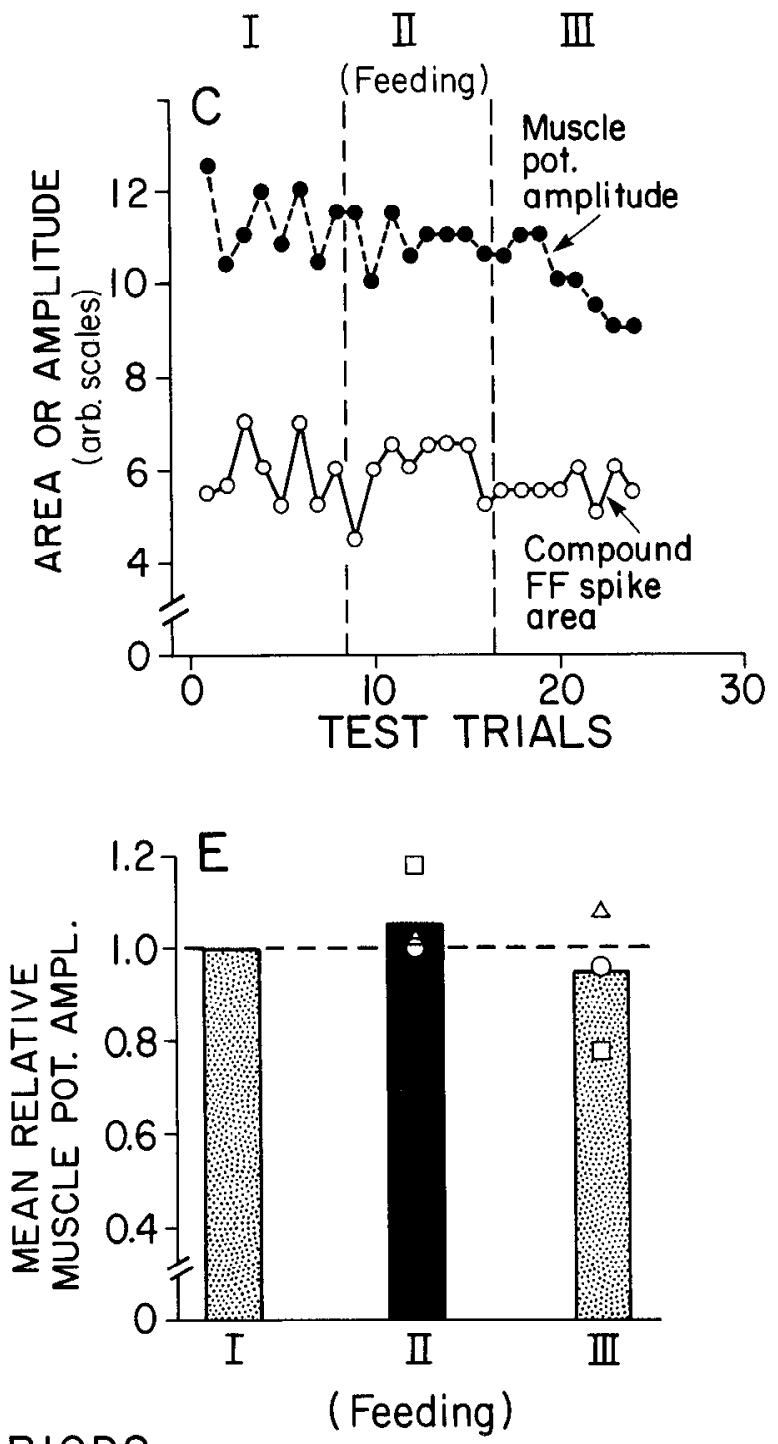

Figure 6. Lack of effect of feeding on recruitment of nongiant fast flexor motor neurons or phasic flexor muscle activity by segmental giant firing. $A$, Sites of stimulation $(S)$ and recording $(R) . F$, Recorded responses to stimuli just below $\left(B_{1}\right)$ and just above $\left(B_{2}\right)$ threshold for SG firing. The upper trace, which is from an electrode on the dorsal surface of the 4-5 connective, monitors 12 firing (filled circle), and the lower trace, on a second ganglion flexor motor root, displays the compound FF action potential (arrowhead). Both traces show volume-conducted flexor muscle potentials $(M)$. The small spikes on the upper trace in $B_{1}$ are presumably sensory interneuron discharges evoked by the first root stimulus used to recruit SGs. Calibration, 2 msec. $C$, Illustrative experiment showing areas of compound FF spikes and amplitudes of muscle potentials evoked by $S G$ firing during periods I-III. There appears to bc no cffect of fccding (which occurred throughout period II). $D, E$, Summarized results for the 3 preparations examined. Means for individual preparations are indicated by square, circular, and triangular markers; mean across these preparations by bars. There is no sign that transmission in this portion of the circuit is inhibited during feeding.

1984), could be suppressed; or the "entry-level" neurons of the circuit, the LGs, could be suppressed. Suppression of LGs would perhaps be most efficient in terms of number of targets that need to be reached by a control pathway, but logically, any of the several possible means could be successful.

However, the circuit is not used only for producing LG escape. Portions of it are also involved in non G (and MG) escape response production, and during consumption of portable food, non $G$ escape responses increase in probability while LG responses are suppressed (Bellman and Krasne, 1983). Thus, control at the FF and I2/3, etc. level becomes unsatisfactory, because suppression of LG escape would then also interfere with non $G$ escape. We do not know whether differential control of LG and MG reactions ever occurs, but if it does, control at the
MoG and SG levels would also be untenable because of lack of sufficient specificity, and only control via the entry-level neurons of this assemblage would remain a useful option. Our data indicate that this is in fact the tactic employed.

Note, in this example, that the essential characteristics of a viable suppressive control option are that the neurons or processes controlled must be sufficient to shut the behavior off fully (i.e., be "pivotal") and be dedicated to the to-be-suppressed response class so that other responses are not affected. In this case, the whole assemblage of neurons is dedicated to tailflip escape production, and certain partially overlapping subsets of the population are dedicated to specific types of escape. Note also that selective control via the entry-level neurons, which is the only type of fully selective control possible in this instance, 


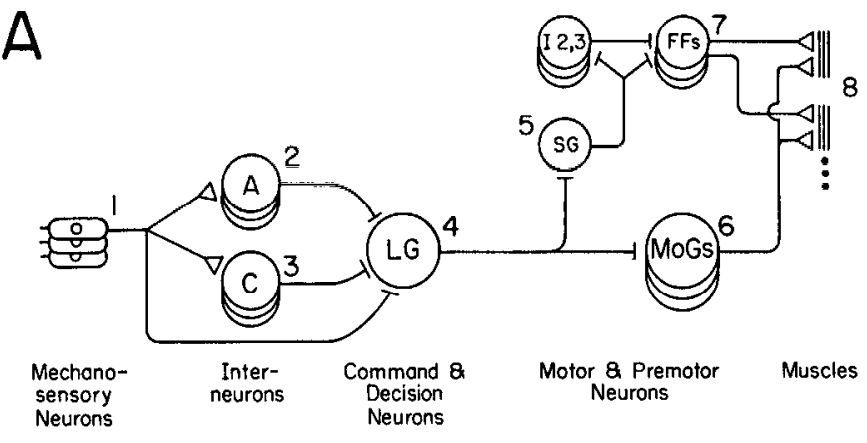

B TRANSMISSION POINTS TESTED DURING FEEDING

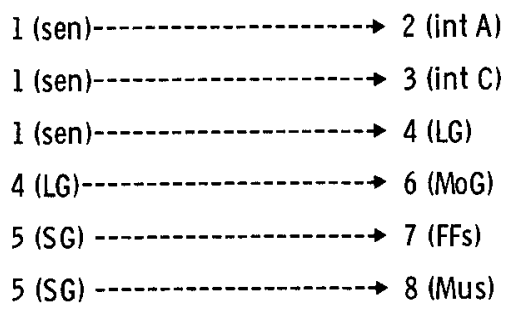

Normal

Normal

Reduced

Normal

Normal

Normal

Figure 7. Summary of results. See text.

depends critically on the segregation of these entry-level neurons with respect to type of escape response. If this were not the case-i.e., if different types of escape were elicited by activity in intersecting sets of entry-level neurons-then differential control of cach type of escape would probably not be possible; furthermore, other design problems that are effectively solved by having response-dedicated neurons would also arise (Krasne and Wine, 1987).

In general, the notion that different specific routines of a given multifunctional pattern-generating module might each be as- sociated with dedicated, segregated sets of processing elements is controversial, the common alternative view being that any given pattern is usually called and initiated by activity in an ensemble of neurons, each member of which is involved in calling other patterns as well. At least one factor motivating this belief is that the dedication of specific entities to only one pattern seems uneconomical. However, the use of dedicated elements may well reduce complexity and increase economy when the requirements of calling and selectively controlling individual patterns of a multifunctional pattern generator are considered.

The pyloric pattern generator of the lobster stomatogastric ganglion is particularly instructive in this regard (Harris-Warrick and Flamm, 1986). A number of transmitters or neurohormones have been identified, each of which specifies the gencration of a particular output pattern from a set of possible patterns that can be generated by the circuit. Each such agent has specific effects on almost every neuron of the pattern-generating network, causing a variety of actions, such as altered endogenous bursting capabilities, inhibition, altered synaptic efficacies, etc. In principle, each of a number of possible response patterns of this network could be recruited, or their probability controlled, by regulating the release or the effectiveness of the appropriate neurohormone or transmitter. In effect, the release of a particular agent to the network would then be acting as a pivotal, pattern-dedicated event via which a pattern could be controlled; recruiting and controlling a specific pattern, without altering the ability of the network to generate others, would thereby be greatly simplified. However, available evidence suggests that, in vivo, the ganglion may in fact generate patterns that result from the release of various partially overlapping combinations of the neurohormones or transmitters. Thus, there is not a one-to-one association between patterns and agents. Of course, pattern-dedicated elements that dictate specific profiles of transmitter release to the pyloric circuit might still be found at higher levels.

In a number of other multifunctional pattern-generator cir-

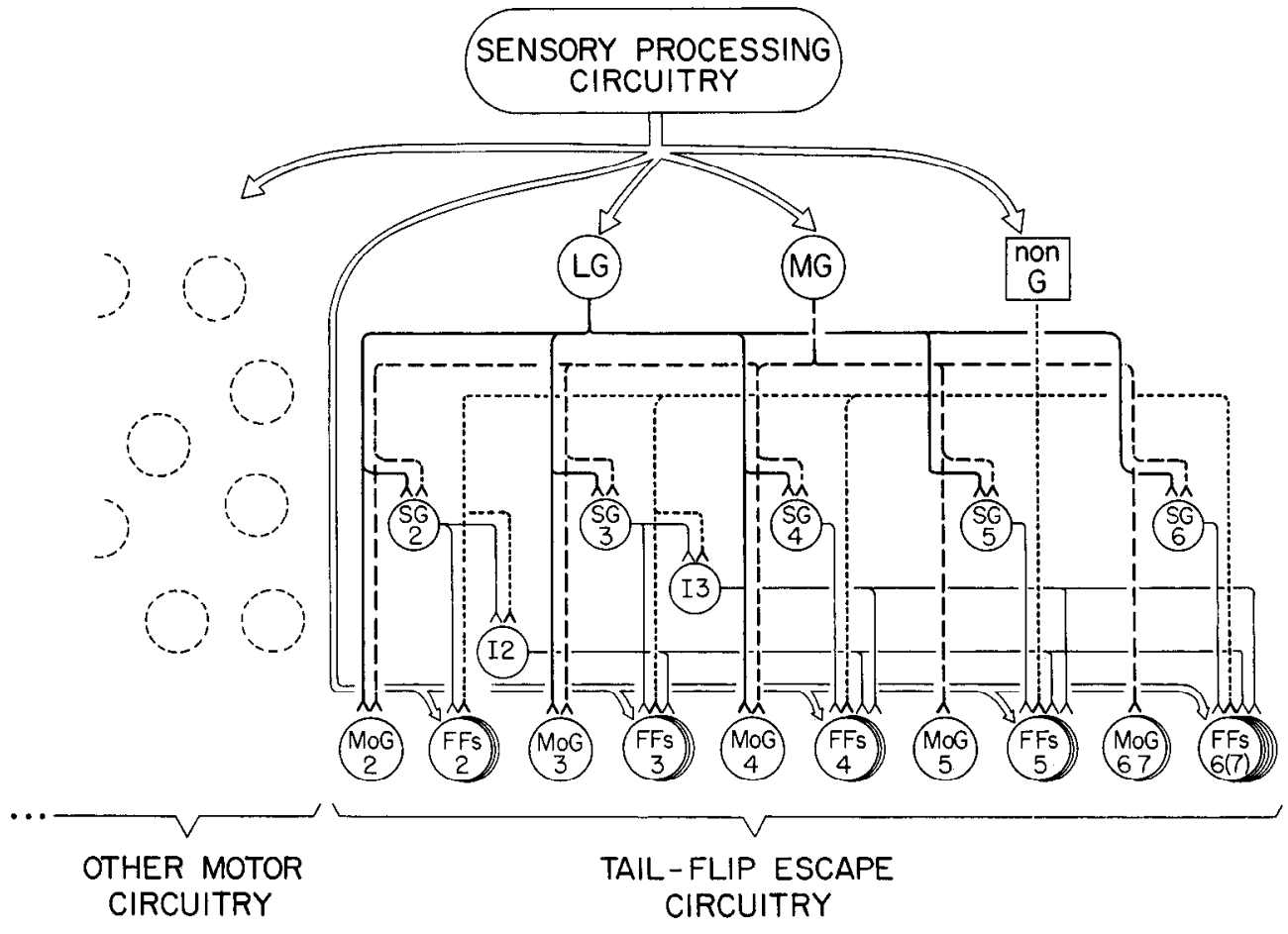

Figure 8. Pattern-generating circuitry for escape. See text. The motor circuit of previous figures has been expanded to indicate segmental distribution of elements (segments 2-6(7) shown; ganglion 6 is a fusion of ancestral 6th and 7 th ganglia). Note (1) that LG projects to rostral MoGs only, whereas MG projects to all MoGs, and (2) that the sensory influence, facilitatory or inhibitory, on FFs indicated by the white arrows contributes to the form of the tailflip; these features are responsible for the upward trajectory of $\mathbf{L G}$ tailflips as compared to the backward trajectory of MG tailflips. 
cuits that have been studied, few pattern-dedicated neurons have been found. Rather, most interneurons and motor neurons participate in the production of a number of patterns (Kennedy and Davis, 1977; Stein, 1978; Fraser, 1982; Simmers and Bush, 1983; Croll et al., 1985a; Grillner and Wallen, 1985; Hcitler, 1985; Mpitsos and Cohen, 1986). However, we would conjecture that, in most such cases, either the different possible patterns of these circuits are not in fact subject to differential control, or dedicated elements may be expected at a higher level of the circuit than has yet been examined (see especially discussions of Croll et al., 1985b, and Heitler, 1985).

\section{References}

Bellman, K. L., and F. B. Krasne (1983) Adaptive complexity of interactions between feeding and escape in crayfish. Science 221: 779781

Berkinblit, M. B., T. G. Deliagina, A. G. Feldman, I. M. Gelfand, and G. N. Orlovsky (1978a) Generation of scratching. I. Activity of spinal interneurons during scratching. J. Neurophysiol. 41: 10401057

Berkinblit, M. B., T. G. Deliagina, A. G. Feldman, I. M. Gelfand, and G. N. Orlovsky (1978b) Generation of scratching. II. Nonregular regimes of generation. J. Neurophysiol. 41: 1058-1069.

Bernstein, N. (1967) The Coordination and Regulation of Movements, Pergamon, Oxford, UK.

Brodfuehrer, P. D., and W. O. Friesen (1986) From stimulation to undulation: A neuronal pathway for the control of swimming in the leech. Science 234: 1002-1004.

Croll, R. P., W. J. Davis, and M. P. Kovac (1985a) Neural mechanisms of motor program switching in the mollusc Pleurobranchaea. I. Central motor programs underlying ingestion, egestion, and the "neutral" rhythm(s). J. Neurosci. 5: 48-55.

Croll, R. P., M. P. Kovac, W. J. Davis, and E. M. Matera (1985b) Neural mechanisms of motor program switching in the mollusc Pleurobranchaea. III. Role of the paracerebral neurons and other identified brain neurons. J. Neurosci. 5: 64-71.

Dumont, J. P. C., and J. J. Wine (1987) The telson flexor neuromuscular system of the crayfish. III. The role of feedforward inhibition in shaping a stereotyped behavior pattern. J. Exp. Biol. 127: 295311.

Eaton, R. C. (1984) Neural Mechanisms of Startle Behavior, Plenum, New York

Flamm, R. E., and R. M. Harris-Warrick (1986a) Aminergic modulation in lobster stomatogastric ganglion. I. Effects on motor pattern and activity of neurons within the pyloric circuit. J. Neurophysiol. 55: 847-865.

Flamm, R. E., and R. M. Harris-Warrick (1986b) Aminergic modulation in lobster stomatogastric ganglion. II. Target neurons of dopamine, octopamine, and serotonin within the pyloric circuit. J. Neurophysiol. 55: 866-881.

Fraser, P. J. (1982) Views on the nervous control of complex behavior. In The Biology of Crustacea, vol. 4, D. C. Sandeman and H. L. Atwood, eds., pp. 293-319, Academic, New York.

Glanzman, D. L., and F. B. Krasne (1983) Serotonin and octopamine have opposite modulatory effects on the crayfish's lateral giant escape reaction. J. Neurosci. 3: 2263-2269.

Glanzman, D. L., and F. B. Krasne (1986) 5,7-Dihydroxytryptamine lesions of crayfish serotonin-containing neurons: Effect on the lateral giant escape reaction. J. Neurosci. 6: 1560-1569.

Grillner, S., and P. Wallen (1985) Central pattern generators for locomotion, with special reference to vertebrates. Annu. Rev. Neurosci. 8: 233-261.

Hagiwara, S. (1958) Synaptic potential in the motor giant axon of the crayfish. J. Gen. Physiol. 41:1119-1128.

Harris-Warrick, R. M., and R. E. Flamm (1986) Chemical modulation of a small central pattern generator circuit. Trends Neurosci. 10:432437.

Heitler, W. J. (1985) Motor programme switching in the crayfish swimmeret system. J. Exp. Biol. 114: 521-549.

Kennedy, D., and W. J. Davis (1977) Organization of invertebrate motor systems. In Cellular Biology of Neurons; Handbook of Physiology, The Nervous System, sect. 1, vol. 1, pt. 2, E. R. Kandel, ed., pp. 1023-1087, American Physiological Society, Bethesda, MD.
Kovac, M. P., and W. J. Davis (1980) Neural mechanisms underlying behavioral choice in Pleurobranchaea. J. Neurophysiol. 43: 469-487.

Kramer, A. P., and F. B. Krasne (1984) Crayfish escape behavior: Production of tailflips without giant fiber activity. J. Neurophysiol. 52: 189-211.

Kramer, A. P., F. B. Krasne, and K. L. Bellman (1981) Different command ncurons select different outputs from a shared premotor interneuron of crayfish tail-flip circuitry. Science 214:810-812.

Krasne, F. B. (1969) Excitation and habituation of the crayfish escape reflex: The depolarizing response in lateral giant fibres of the isolated abdomen. J. Exp. Biol. 50: 29-46.

Krasnc, F. B., and D. L. Glanzman (1986) Sensitization of the crayfish lateral giant escape reaction. J. Neurosci. 6: 1013-1020.

Krasne, F. B., and S. H. Lee (1977) Survival of functional synapses on crustacean neurons lacking cell bodies. Brain Res. 121: 43-57.

Krasne, F. B., and J. J. Wine (1975) Extrinsic modulation of the crayfish escape behavior. J. Exp. Biol. 63: 433-450.

Krasne, F. B., and J. J. Wine (1984) The production of craytish tailflip escape responses. In Neural Mechanisms of Startle Behavior, pp. 179211. Plenum, New York.

Krasne, F. B., and J. J. Wine (1987) Evasion responses of the crayfish. In Aims and Methods in Neuroethology, D. M. Guthrie, ed., U. Manchester Press, UK.

Kravitz, E. A. (1986) Serotonin, octopamine, and proctolin: Two amines and a peptide, and aspects of lobster behaviour. In Fast and Slow Chemical Signalling in the Nervous System, L. L. Iversen and E. Goodman, eds., pp. 244-259, Oxford Science, Oxford, UK.

Kupfermann, I., and K. R. Weiss (1978) The command neuron concept. Behav. Brain Sci. 1: 3-39.

McClelland, J. L., and D. E. Rumelhart (1986) Parallel Distributed Processing: Explorations in the Microstructure of Cognition, vol. 2 Psychological and Biological Models, MIT Press, Cambridge, MA.

Mittenthal, J. E., and J. J. Wine (1973) Connectivity patterns of crayfish giant interneurons: Visualization of synaptic regions with cobalt dye. Science 179: 182-184.

Mpitsos, G. J., and C. S. Cohen (1986) Convergence in a distributed nervous system: Parallel processing and self-organization. J. Neurobiol. 17: 517-545.

Reichert, H., and J. J. Wine (1983) Coordination of lateral giant and nongiant systems in crayfish escape behavior. J. Comp. Physiol. 153: 3-15.

Roberts, A. M., F. B. Krasne, G. Hagiwara, J. J. Wine, and A. P. Kramer (1982) The segmental giant: Evidence for a driver neuron interposed between command and motor neurons in the crayfish escape system. J. Neurophysiol. 47: 761-781.

Rumelhart, D. E., and J. L. McClelland (1986) Parallel Distributed Processing: Explorations in the Microstructure of Cognition, vol. 1: Foundations, MIT Press, Cambridge, MA.

Selverston, A. I., and A. P. Remler (1972) Neural geometry and activation of crayfish fast flexor motoneurons. J. Neurophysiol. 35:797814.

Sigvardt, K. A., G. Hagiwara, and J. J. Wine (1982) Mechanosensory integration in the crayfish abdominal nervous system: Structural and physiological differences between interneurons with single and multiple spike initiating sites. J. Comp. Physiol. 148: 143-157.

Simmers, J., and B. M. H. Bush (1983) Motor programme switching in the ventilatory system of Carcinus maenas: The neuronal basis of bimodal scaphognathite beating. J. Exp. Biol. 104: 163-181.

Stein, P. S. G. (1978) Motor systems, with specific reference to the control of locomotion. Annu. Rev. Neurosci. 1: 61-81.

Watanabe, A., and H. Grundfest (1961) Impulse propagation at the septal and commissural junctions of crayfish lateral giant axons. J. Gen. Physiol. 45: 267-308.

Wine, J. J., and F. B. Krasne (1972) The organization of escape behavior in the crayfish. J. Exp. Biol. 56: 1-18.

Wine, J. J., and F. B. Krasne (1982) The cellular organization of crayfish escape behavior. In The Biology of Crustacea, vol. 4, D. C. Sandeman and H. L. Atwood, eds., pp. 241-292, Academic, New York.

Wine, J. J., and D. C. Mistick (1977) Temporal organization of crayfish escape behavior: Delayed recruitment of peripheral inhibition. J. Neurophysiol. 40: 904-925.

Wine, J. J., F. B. Krasne, and L. Chen (1975) Habituation and inhibition of the crayfish lateral giant fibre escape response. J. Exp. Biol. 62: 771-782. 